TABLE 1. Clinical characteristics of patients

\begin{tabular}{|c|c|c|c|c|c|c|c|c|}
\hline \multirow[b]{2}{*}{ Case } & \multirow[b]{2}{*}{ Diagnosis } & \multirow[b]{2}{*}{ Anomaly } & \multirow[b]{2}{*}{ BBW (kg) } & \multirow[b]{2}{*}{ aAo diameter (mm) } & \multirow{2}{*}{$\frac{\text { at PAB }}{\text { Age (d) }}$} & \multicolumn{3}{|c|}{ at $N / G$} \\
\hline & & & & & & Age & BW (kg) & Isthmus diameter (mm) \\
\hline 1 & $\mathrm{AA}, \mathrm{MA}$ & & 3.5 & 2.0 & 17 & 124 & 4.7 & 5.2 \\
\hline 2 & AS, MS & & 3.4 & 5.1 & 7 & 94 & 4.4 & 4.3 \\
\hline 3 & AS, MS, IAS & Chromosome anomaly & 3.2 & 4.4 & 7 & 106 & 3.2 & 7.3 \\
\hline 4 & $\mathrm{AA}, \mathrm{MA}$ & Facial anomaly & 3.1 & 2.7 & 8 & 134 & 4.3 & 5.5 \\
\hline 5 & $\begin{array}{l}\text { AA, MS } \\
\text { VSD }\end{array}$ & $\begin{array}{l}\text { Anal atresia } \\
\text { Ear canal atresia }\end{array}$ & 3.2 & 1.9 & 12 & 149 & 4.1 & 6.2 \\
\hline
\end{tabular}

$A A$, Aortic atresia; $A S$, aortic stenosis; $M A$, mitral atresia; $M S$, mitral stenosis; $I A S$, intact atrial septum; $V S D$, ventricular septal defect; $B B W$, birth body weight; $a A o$, ascending aorta; $P A B$, pulmonary artery banding; $B W$, body weight; $N / G$, simultaneous Norwood Glenn procedure.

procedure. The localized intimal proliferation in this situation is consistent with the developmentally regulated matrix remodeling, which was previously correlated to the postnatal anatomic closure of the duct in newborn lambs. ${ }^{5}$ These findings may be a potential hazard for the long-term ductal opening in limited cases.

Collectively, the present findings may give us a biological basis and a caution for our minimally invasive strategy against HLHS, as well as a fundamental insight into the biology of the "PGE1-opened" arterial duct in humans. Further studies are warranted in this regard.

\section{References}

1. Akintuerk H, Michel-Behnke I, Valeske K, Mueller M, Thul J, Schranz $\mathrm{D}$, et al. Stenting of the arterial duct and banding of the pulmonary arteries: basis for combined Norwood stage I and II repair in hypoplastic left heart. Circulation. 2002;105:1099-103.

2. Bacha EA, Daves S, Hardin J, Abdulla RI, Anderson J, Hijazi ZM, et al. Single-ventricle palliation for high-risk neonates: the emergence of an alternative hybrid stage I strategy. J Thorac Cardiovasc Surg. 2006; 131:163-71.e2. Epub 2005 Dec 5.

3. Takabayashi S, Shimpo H, Ozu Y, Yokoyama K, Kajimoto M. A Fontan completion through stage I bilateral pulmonary artery banding for hypoplastic left heart syndrome. J Thorac Cardiovasc Surg. 2005; 130:1464-5.

4. Clyman RI, Mauray F, Heymann MA, Roman C. Influence of increased pulmonary vascular pressures on the closure of the ductus arteriosus in newborn lambs. Pediatr Res. 1989;25:136-42.

5. Rabinovitch M. Cell-extracellular matrix interactions in the ductus arteriosus and perinatal pulmonary circulation. Semin Perinatol. 1996; 20:531-41.

\title{
Hybrid procedure for the neonatal management of pulmonary atresia with intact ventricular septum
}

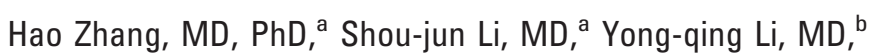
Hao Wang, MD, PhD, ${ }^{b}$ and Sheng-shou Hu, MD, Beijing, China

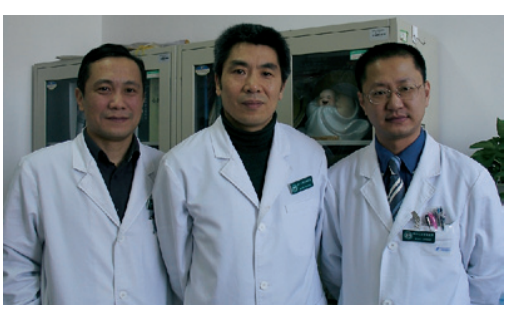

Drs Li, Hu, and Zhang (left to right)
From the Center for Pediatric Cardiac Surgery a and the Department of Echocardiography, ${ }^{\mathrm{b}}$ Cardiovascular Institute and Fu Wai Hospital, Chinese Academy of Medical Science, Beijing, China.

Received for publication Jan 30, 2007; accepted for publication Feb 6, 2007.

Address for reprints: Sheng-Shou Hu, MD, Department of Cardiac Surgery, Cardiovascular Institute and Fu Wai heart Hospital, Chinese Academy of Medical Sciences, 167A Beilishilu, Beijing 100037, P.R. China (E-mail: shengshouhu@yahoo.com).

J Thorac Cardiovasc Surg 2007;133:1654-6

$0022-5223 / \$ 32.00$

Copyright $\odot 2007$ by The American Association for Thoracic Surgery doi:10.1016/j.jtcvs.2007.02.002

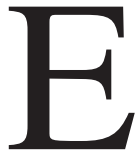
arly decompression of the right ventricle (RV) is crucial for the neonatal management of pulmonary atresia with intact ventricular septum (PAIVS) without abnormalities of the coronary artery circulation. We developed a novel hybrid beating heart procedure for the management of PAIVS.

\section{Clinical Summary}

From March 2005 through January 2007, 4 neonates (3-4.5 kg) with PAIVS were treated with the hybrid procedure in the first week after birth. All newborns received preoperative prostaglandin $\mathrm{E}_{1}$ infusion. The $\mathrm{Z}$ value of the tricuspid valve diameter was $-1.5,-2,-2$, and 1.5 separately, which was measured by means of 2-dimensional echocardiography. All newborns had a patent infundibulum, and absence of the trabecular portion occurred in 1 case. 


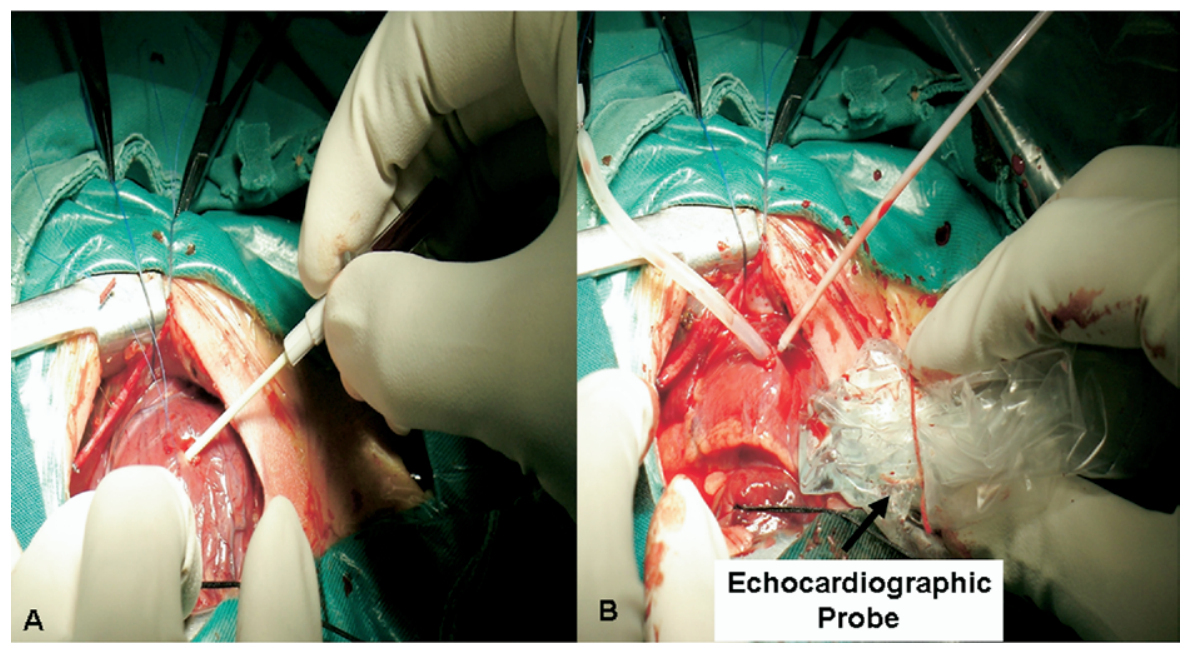

Figure 1. Scheme of the hybrid procedure. A, Puncture through the right ventricle free wall. $B$, Balloon valvuloplasty guided with epicardial echocardiography.

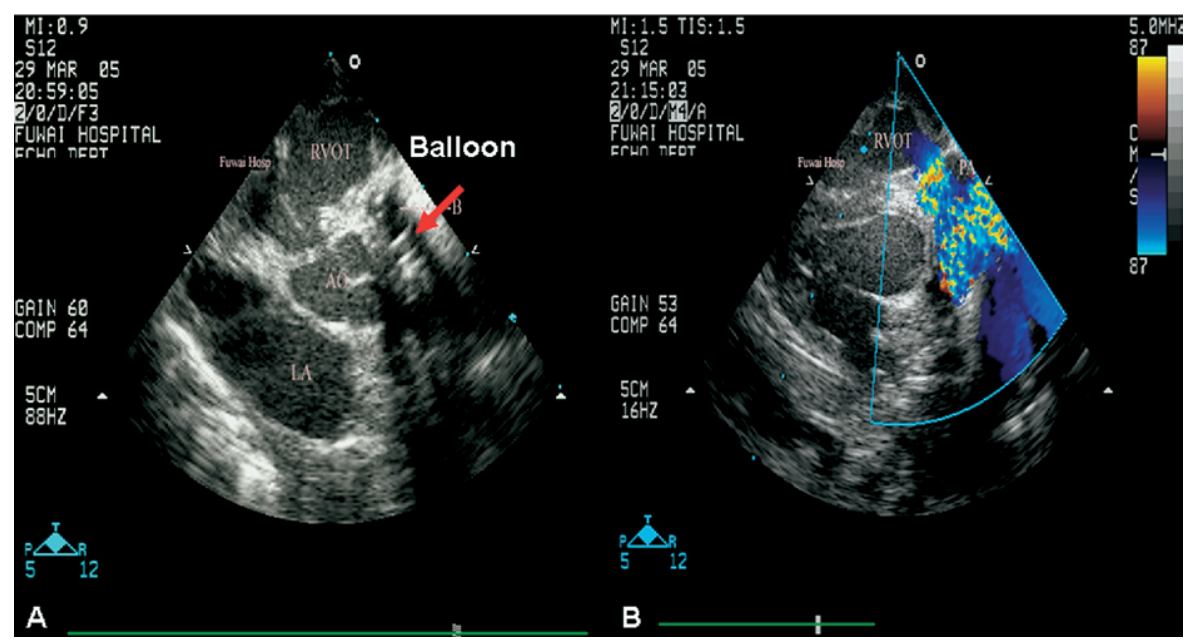

Figure 2. Balloon valvuloplasty guided with epicardial echocardiography. A, The atretic pulmonary valve. $B$, Full opening of the pulmonary valve after repeated balloon dilation.

The heart was exposed with a midline sternotomy. A pursestring suture was placed in the right ventricular outflow tract (RVOT) $2 \mathrm{~cm}$ away from the pulmonary trunk. The operator held the echocardiographic probe in the subxiphoid to capture a clear image for the atretic pulmonary valve (PV), and then a 16-gauge intravenous catheter (BD Angiocath, Infusion Therapy Systems) was punctured perventricularly and perforated the PV. A guide wire was then inserted into the sheath and used to guide the balloon (Numed) across the PV (Figure 1). Sequential dilations were performed until a full opening of the PV with the guidance of epicardial echocardiography was obtained (Figure 2). A 3.5-mm modified Blalock-Taussig (BT) shunt was placed after successful balloon valvuloplasty. Finally, the prostaglandin infusion was ceased, and the patent ductus arteriosus was ligated.

The newborns were ventilated for 6 to 72 hours after the operation. They were discharged with arterial oxygen saturation values of $75 \%$ to $88 \%$. No additional procedures were needed, and both growth of the RV and body weight were regained during the follow-up period (1-23 months). Mild PV stenosis was observed in 1 child, and mild-to-moderate PV regurgitation was seen in all children. One child with a well-developed RV was scheduled for percutaneous occlusion for the BT shunt to achieve definitive repair, and another with relatively right ventricular hypoplasia was scheduled for a bidirectional Glenn procedure. The other 2 patients, with arterial oxygen saturation values of $87 \%$ to $91 \%$, were still waiting for adequate growth of the RV.

\section{Discussion}

With the development of catheter-based devices, percutaneous catheter-based therapy has been advocated for neonates with a patent infundibulum and a lack of RV-dependent coronary circulation. ${ }^{1}$ However, percutaneous perforation and balloon valvuloplasty were associated with higher rates of procedural failure and serious complications. Unfortunately, even after successful percutaneous balloon valvuloplasty, $43 \%$ to $51 \%$ of neonates needed urgent procedures, including BT shunt placements, RVOT recon- 
struction, or both. ${ }^{2,3}$ Furthermore, in developing countries percutaneous laser- or radiofrequency-assisted perforation for neonates is far from popular and can be performed in very few centers. Hence, in general neonates with PAIVS were referred to the surgical department in our center. Surgical approaches, including RVOT reconstruction with a transannular patch and transventricular/pulmonary valvotomy, were also attempted to achieve right ventricular decompression; however, the mortality was considerably high. ${ }^{4}$ Based on the above facts, we integrated the catheterbased devices and the traditional surgical procedure for PAIVS as initial management.

In this hybrid beating-heart procedure, first we perforate the PV with the needle and then deliver the balloon through the RV free wall to the pulmonary trunk. Epicardial echocardiography was used not only to guide the procedure with real-time imaging but also to evaluate the effectiveness of valvuloplasty with monitoring of the trans-PV flow and gradient pressure. In percutaneous catheter therapy, if the newborn could not be weaned from the prostaglandin infusion, an urgent BT shunt would be considered. Such a delayed decision could result in postoperative hypoxia and thus increased mortality. Because the operative field was offered by the open-chest approach, we regularly placed a BT shunt simultaneously. Ligation of the patent ductus arteriosus was performed to prevent the excess augmentation of blood flow to the lung, and then prostaglandin infusion was ceased immediately in the operating room.
We have not yet applied the hybrid procedure for PAIVS in a patient with a severely hypoplastic RV. Theoretically, such a hybrid procedure would augment the antegrade flow and offer the chance of development of the RV; therefore it was also beneficial for this subgroup.

In conclusion, our results show that, combined with real-time echocardiographic guidance and a catheter-based device, the hybrid procedure could be a good alternative to percutaneous catheter-based therapy for selected neonates with PAIVS, especially in centers in developing countries where the materials for percutaneous perforation are not available and the experience with neonatal percutaneous catheter therapy is limited.

We thank the National Eleventh-Five Year Project and Beijing Nova Project (2006 A85).

\section{References}

1. Humpl T, Söderberg B, McCrindle BW, Nykanen DG, Freedom RM, Williams WG, et al. Percutaneous balloon valvotomy in pulmonary atresia with intact ventricular septum: impact on patient care. Circulation. 2003;108:826-32.

2. Mclean KM, Pearl JM. Pulmonary atresia with intact ventricular septum: initial management. Ann Thorac Surg. 2006;82:2214-20.

3. Agnoletti G, Piechaud JF, Bonhoeffer P, Aggoun Y, Abdel-Massih T, Boudjemline $Y$, et al. Perforation of the atretic pulmonary valve: longtime follow up. J Am Coll Cardiol. 2003;41:1399-403.

4. Bull C, Kostelka M, Sorensen K, de Leval. Outcome measures for the neonatal management of pulmonary atresia with intact ventricular septum. J Thorac Cardiovasc Surg. 1994;107:359-66.

\title{
Reduced regional right ventricular wall motion after transventricular repair of tetralogy of Fallot
}

\author{
Shin Takabayashi, MD, PhD, ${ }^{a}$ Hideto Shimpo, MD, PhD, ${ }^{a}$ Kazuto Yokoyama, MD, ${ }^{a}$ Koji Onoda, MD, PhD, and \\ Yoshihide Mitani, MD, PhD, ${ }^{\mathrm{b}}$ Mie, Japan
}

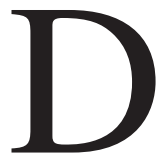

uring intracardiac repair of tetralogy of Fallot (TOF), a larger right ventriculotomy provides better exposure of ventricular structures. However, right ventricular (RV) function is impaired after ventriculotomy, and a previous report suggests that ventriculotomy reduces regional wall

From the Departments of Thoracic and Cardiovascular Surgery a and Pediatrics, ${ }^{\text {b }}$ Mie University Graduate School of Medicine, Mie, Japan.

Received for publication Feb 19, 2006; accepted for publication March 5, 2006.

Address for reprints: Shin Takabayashi, MD, Department of Thoracic and Cardiovascular Surgery, Mie University Graduate School of Medicine, 2-174, Edobashi, Tsu, Mie 514-8507, Japan (E-mail: shin1111@clin.medic.mie-u.ac.jp).

J Thorac Cardiovasc Surg 2007;133:1656-8

$0022-5223 / \$ 32.00$

Copyright $\odot 2007$ by The American Association for Thoracic Surgery doi:10.1016/j.jtcvs.2007.03.001 motion around the $\mathrm{RV}$ incision. ${ }^{1}$ To investigate the impact of right ventriculotomy on regional $\mathrm{RV}$ wall function, we used postoperative lateral RV angiocardiography to compare segmental fractional shortening (FS) after transventricular and transpulmonarytransatrial TOF repair.

\section{Clinical Summary}

We studied 28 consecutive patients who underwent TOF repair between 1994 and 1998. They were divided into two groups: the first 14 patients underwent transventricular repair (group V) and the other 14 underwent transatrial-transpulmonary repair (group A). The mean age (2.9 vs 2.6 years), weight (13.0 vs $11.4 \mathrm{~kg}$ ) and preoperative RV function were not significantly different between group $\mathrm{V}$ and group $\mathrm{A}$. Three patients in group $\mathrm{V}$ had undergone a prior operation (systemic-pulmonary shunt, 2; Brock, 1), and 1 patient in group A had undergone a systemic-pulmonary shunt. A transannular patch repair was performed in 9 patients in each group. Definitive repair by ven- 